are confused, and the patient at the same time experiences a sensation as if he were about to become insensible. If he stoops, he is apt to be seized with temporary blindness, the hearing is inordinate'y acute, the least noise rendering him almost distracted; he is frequently troubled with a buzzing sound, and sometimes with other noises in the ears; flushings and heat pass at times over the head and face; the hair is often tender and painful when touched, and the scalp feels hot, constricted, and uneasy. With respect to the general symptoms which attend upon this state, they are such as indicate a disordered condition of the digestive appiratus, and an ill-regulated and badly-formed secretion.

The function of digestion is most frequently very imperfectly performed; flatulence, with acid eructations; a sense of weight and general uneasiness at the pit of the stomach; rumbling in the bowels; an unpleasant acid or bitter taste in the mouth; the tongue furred with a brown fur, with occasional yellow streaks; a disordered state of the bowels, which are sometimes confined and at others much relaxed, the stools being generally clay-coloured, shewing a deficiency of bile, or else very high-coloured, dark, and offensive, showing a redundancy of that excretion, but in a very unhealthy state; the urine unusually scanty, and high coloured, and depositing a reddish sediment on standing, with a rough dry skin, are symptoms which indicate a general disarrangement, and an imperfect performance of the ordinary functions of the body, by which the effete matter of the frame is got rid of by means of the secretions and excretions, and fresh pabulum or material furnished to supply the waste of the system. Meanwhile, in the midst of much disorder of the secretive apparatus, the pulse generally remains undisturbed, or, if at all altered, shows a diminished rate of circulation, - a lessened degree of tone in the system.

The symptoms are those that are found to be placed almost beyond the possibility of a doubt. It is the result, I conceive, of a morbid condition in the function of sanguification, or perhaps of the immediate preparatory process or chylification, by a failure on the part of the kidneys to perform rightly their secerning duties, by which the separation of urea and uric acid upon the blood should be effected. The presence of this acid in the circulating medium, then, may be regarded as characteristic of the gout, and the fact ascertained by Chelius, of Heidelburgh, that in the course of twelve days, under the administration of colchicum, the kidneys are excited to abstract from the blood nearly double the quantity of uric acid they had previously separated, will amply serve to explain the remedial influence of colchicum in the relief of the disease, and the manner in which the influence is excited.

2, Soho Square.

[To be continued.]

\section{ON THE PROGRESS}

oF

\section{PUBLIC HYGIẼNE AND SANITARY} LEGISLATION IN ENGLAND,

\section{AND THE ADVANTAGES TO BE DERIVED FROM THEIR FURTHER EXTENSION.*}

\section{BY J. I N G H A M I K I N, Esa.,}

Fellow of the Royal Collegt of Surgeons of England, and Lecturer on Anatomy and Physiology in the Leeds School of Medicine, etc.

Read before the Leeds Philosophical Society, March, 1851.

IN March, 1842, $\uparrow$ a Select Committee was appointed to consider the expediency of framing some legislative enactment to remedy the evils arising from the interment of bodies within the precincts of large towns, or of places densely populated. Mr. Mackinnon took the lead in this inquiry, and our member Mr. Beckett, was an active member of the Committee. The result of this inquiry, and of the mass of evidence given, showing the injurious and pernicious results arising from this interment within towns, was the report "that the practice of interment within the precincts of large towns is injurious to the health of the inhabitants thereof, and frequently offensive to public decency; and that it was expedient to pass an Act of Parliament to prevent it, with some few exceptions." The other recommendations and particulars it is unnecessary to dwell upon. The construction of new cemeteries was one of the good results; and after some squabbling we succeeded in abtaining two large

- Continued from nage 543.

+ I append a list of local sanitary reports made to Gorernment through the Poor-Law Commissioners* before the general inquiry by a Committee of the House of Commons in $1842:-$

A report from Mr. Hodgson and a Committee of medical gentlemen of Birmingham on the sanitary condition of the labouring population of that town.-A report on the sanitary condition of the dwellings of the labouring classes, \&c., in Manchester, from Dr. Baron Howard, Physician to the Ardwick and Ancoats Dispensary of that town.-Also one on the condition of the labouring population in Liverpool, from Dr. Duncan.One on the condition of the labouring population in Derby, from Dr. Barker. One on the condition of the labouring populatinn of Truro, Barker. One on the condition of the labouring population of Truro,
from Dr. Barham.-One on the condition of the labouring population of Brighton, from Dr. Jenks.- One on the sanitary condition of the labouring population in the town of Wolverhampton, by Dr. Dehane.-One on the prevalence of fever in the parish of Breadsall, Derbyshire, by Dr. Kennedy and Mr. Senior.-One on the sanitary state of the town of Stafford, by Dr. Edward Knight.-One on an improved condition of the town of Lancaster, by Dr. de Virtrie.-One on the sanitary condition of the town of Leeds, by Mr. Robert Baker.

Twelve reports from medical men on the sanitary state of towns and districts in Scotland, were appended also to this report of the Poor-Law Conmissioners, besides many others from clergymen, magistrates, and other parties of local influence in different parts of the country; but it is quite impossible in a paper of this kind to enumerate all.

Two very recent publications connected with hygiène I must here, however, notice, as they contain many useful practical suggestions, and the author of them has given his attention to such matters for some years. One is a pamphlet " $O n$ the Contamination of $W_{\text {ater }}$ by the Poison of Lead, and its effects on the Human Body," by James Bower Harrison, Esq., Surgeon, Manchester; and a recent letter of his to the Earl of Shaftesbury, containing "Suggestions as to the Expediency of Submitting certain Brancbes of Trade and Manufactures to Government Medical Inspection." Dr. Calvert Holland also has written ably on the injurious effects of grinding steel.

- "The Report to the Secretary of State from the Poor-Law Commissioners on an Inquiry into the Sanitary Condition of the Lahouring population of Great Britain." This report, indeed, laid the foundation for Legislative interference with regard to the public health, and has proved invaluable. It should have been published in a cheap and abridged form. 
and conveniently-situated cemeteries for our own town, besides those in the out townships. The exertions of Mr. Walker, regarding the exposure of the injurious effects of intramural interment in London, have been beyond all praise; and his work entitled "Gatherings from Grave Yards," did more than anything to rouse public feeling on this question. The question, as regards London, has not yet been satisfactorily settled, though in one of the latest reports on the subject, by the Board of Health, an adequate and satisfactory general scheme for extramural sepulture seems to be decided upon. But these reports we sinall have to allude to directly, as they come last in order, and are of quite recent date. It was also in the year 1842 that the Loeds Improvement Act passed, and one also for Liverpool, in which latter town the mortality has always been high. These Acts were great steps in advance of most other towns, with regard to sanitary reform. But many of the clauses of the Leeds Act are scarcely efficient, so that the spirit of the Act does not seem always to be successfully carried into practice. Doubtless this will be remedied before long. But it is only due to the town in which wo live, which all are so ready to run down and depreciate, on account of its smoke and dust, and in answer to the constantly-repeated charge of want of public spirit (which one must admit is not altogether ill founded) of its inhabitants, for me to state that Leeds is behind few large towns in the kingdom in some of the most essential requirements for the health and comfort of its inhabitants. Our sanitary charities are all excellent, viz., our Infirmary, House of Recovery, and Dispensary. Again, our School of Industry is a fine institution ; our gaol,* unfortunately, is of national celebrity, and a model in its way. With regard to the grand desideratum-a good supply of water, - that we ought to have, for the price we have to pay for it. Our plan of sewerage, now carrying out, I hope will be as efficient as engineering skill can make it. Intramural interment is forbidden, with few exceptions, and our cemeteries only require plants, shrubs, and walks to render them very complete and appropriate receptacles for the dead. For relaxation we have our unrivalled moar. But what we want is a more general taste for architectural beauty and ornament, a better looking class of houses, public monuments, adequate town walks and promenades, and public buildings. Our market is much improved and enlarged. Fountains, and other improvements and embellishments, have been suggested. We are now getting a handsome class of churches and chapels, though much money has been thrown away in distasteful church and chapel architecture in this town. Still, looking at Leeds without prejudice, the place may be said to be like its inhabitants ; it has considered first the useful-the ornamental and elegant are secondary considerations, to follow in due course. $\dagger$

- The gaol is a fine large building, in a most commanding situation, and its magnitude is such that the Government send a great number of felons for confinement in it. It is, undoabtedly, a well-conducted, wellarranged, and model building of its kind,-I.

t A Public Improvement Society is junt eatabliahed in Leeds, whicb may do great good, and atimulate public opinion in these matters-I.
To return : the names included in the commission for inquiry into the state of large towns, are a sufficient guarantee that the inquiry would be an efficient one, and the report a practical as well as a scientific and correctone. Among the names we have Buccleugh, Lincoln, Slaney, Graham, De La Bèche, Lyon Playfair, Reid, Owen, Martin, Smith, Stephenson, Cubitt, \&c. The principal points embraced in the commission, were " the causes of death among the inhabitants ; the best means of promoting and securing the public health under the operation of the laws and regulations now in force, and the usages at present prevailing with regard to the drainage of lands; the erection, drainage, and ventilation of buildings; and the supply of water in such towns and districts, whether for the purposes of health, or for the better protection of property from fire; and how far the public health and the poorer classes of the people of this realm, and the salubrity and safety of their dwellings may be promoted by the amendment of such laws, regulations, and usages." Here we have, then, a most adequate and plain proposition devising a system of public hygiène for the United Kingdom. "The land (says the British and Foreign Medical Review, 1844), of mines and machinery ; of railways and steam ships; the land of an overflowing industrious, energetic population; the land of unceasing action; the sun and centre of modern civilization; the beacon set up as a guide to all nations," now at length fairly sets to work to devise some comprehensive measure on a vitally important question, and to propose some remedy for a wide-spreading and growing evil. I find there were above sixty witnesses called before this commission; and the main witnesses on the general subject are practical men; and the local reports of different towns are also introduced, and which have been principally made by physicians and surgeons, and various clergymen-viz., Dr. Duncan, for Liverpool ; Dr. Laycock, for York. The names of Drs. Arnott, Clark, S. Smith, Liddle, Guy, Aldis, Rigby, and Mr. Toynbee appear amongst the host of witnesses. The evidence of Dr. Thomas Clark, of Aberdeen, and Mr. Hawkesley, of Rotherhithe, on the quality and impurities of water is most extensive, instructive, and telling. Dr. Clark distinguishes the whole saline contents of water as the neutral and the alkaline; the latter consists of bicarbonates-those of lime and magnesia, and of potash and soda ; the former of neutral salts of earth and alkalies; the earthy salts are, of course, the cause of hardness, which is a condition not desirable for domestic purposes. Dr. C. estimates the annual value of soap consumed per head in London at $6 \mathrm{~s} .8 \mathrm{~d}$. The total value, including the alkaline base, is $£ 630,000$; so that the difference of cost between the supply of hard and soft water may be estimated for London, at $£ 200,000$.

Dr. Clark also states regarding the presence of organic matters, that such are not separable by filtration. Animalculæ are found to abound in the water of all the London companies; the impurity of London water, doubtless is indirectly a great cause of drunkenness. At the present time there is a comprehensive and apparently 
feasible plan for the supply of London with pure water ; thanks to the labours of such men as we are now alluding to. As regards the supply of water to towns, it is now found to be quite practical to supply every house with an abundance of water at a small cost. The price of water in Leeds, as well as that of gas, is by no means cheap ; and our water-works will have to be enlarged and the supply rendered adequate for the wants of the town, instead of being stinted as at present.* The vitiation of the atmosphere is one of the most important subjects of inquiry in the report; the effects of deficient ventilation, and the general mortality caused thereby occupy a prominent part, as well as the influence of occupation on the health with reference to ventilation. Dr. Duncan's report on Liverpool is particularly valuable. Dr. Guy personally inspected the work-shops of London, and furnished the Commissioners with much valuable information; one of his conclusions is both important and sad, for the proportion of consumption in the three classes of gentlemen, tradesmen and artisans, being respectively about 16,28 , and 30 in the hundred; and this he attributes to confinement for so many hours in in-ventilated shops. That scrofulous diseases result from epidemic visitations, is equally strikingly shown by Mr. Toynbee. The modes of improving ventilation pointed out the injurious effects of an atmosphere rendered impure by miasmata, its effects on the morals, \&c. The use of opiates, drunkenness, infanticide, mortality amonst infants, are all dwelt upon. It appears that in Ashton-under-Lyne opiate mixtures for infants, sold only by fifteen vendors in that town, amounted to the enormous quantity of nearly seven gallons weekly. The over-crowding and filth of common lodging-houses is brought before the notice of the commission, and sanitary regulations with regard to them are recommended. These remarks will show you what an important field of inquiry was entered upon by this valuable report of the Commissioners. About the time this report was published, some useful publications on the sanitary condition of Glasgow and Edinburgh appeared; in relation to the former, one by Dr. Perry, and to the latter, a treatise by that zealous philanthropist and able professional physician, Dr. Wm. Pultney Alison; all who have the pleasure of knowing him can speak of his sterling worth and earnest ability, and his unwearied exertions on behalf of the poor of the city of Edinburgh. "The Contributions to Vital Statistics as a Development of the Rate of Mortality, and the Causes of Sickness, from original and extensive data, procured from Friendly Societies, showing the instability of Friendly Societies, Odd Fellows, \&c., with an Inquiry into the Influence of Locality on Health," by Mr. Neison, and communicated to the statistical society, deserve.mention as valuable contributions connected directly and indirectly with our subject. Also the work of Mr. Hollis, on the

\footnotetext{
- The Corporation of Leeds propose to buy the shares of the Leeds Water Works Company, and go to Parliament for a fresh $\Delta$ ct, in order to supply the town effieiently with water, the present Company not being able to do so. An able report on the water supply of Leeds has just been issued from the Town Clerk's offee, with an excellent speech on the question by Mr. Alderman Shaw.
}

Social and Sanitary Condition of the Working Classes in the City of Dublin". The journal of the Statistical Society also contains much valuable matter connected with public hygiène and vital statistics.

In 1845 the second Report of the Commissioners appeared-a still more important and valuable contribution to public hygiène than the first, and the one that was the immediate cause of the passing of the Health of Towns' Bill or Public Health Act, and the Diseases Prevention Act, and the appointment of the General Board of Health. The Commissioners state in the second Report, that their investigations and reports have excited increased attention to the importance of providing for the physical condition of the poorer inhabitants of large towns, and that the wealthy and intelligent classes resident in them are now, for the most part, becoming alive to this question, and to the necessity of providing for the removal of those causes which tend to vitiate the air, and increase the mortality of the poor in denselycrowded districts. By this active collection and diligent diffusion of information in matters relating to the public health, the reports of the Health of Towns' Commissioners have done the greatest service to the public, and these good results are now beginning to be experienced, as the recent reports of the Registrar-General satisfactorily show. Such laborious results, though not like popular, exciting, political, or theological questions, are in themselves, as stated at the onset, more permanent in their effects, and really more deserving of the title-patriotic. The Commissioners conclude their report with an outline of the measures they propose and recommend, which recommendations formed the groundwork of the Health of Towns' Bill, now in force, and of the contents of which it is unnecessary to give an abstract, as you can refer to it yourselves. We now, then, arrive at the time when drainage, paring, cleansing, and lighting of streets are recommended, as well as the supply of water, to be placed under an administrative body; when additional powers are recommended to be given in this respect both to local authorities and the Government; when the sanitary regulations relative to the construction and ventilation of buildings and the width of streets should be adopted; and when our common lodgingbouses are to be placed under public inspection and controul, and all nuisances put down.

The desirability of these recommendations and measures admits of no dispute; and, as a town, we may congratulate ourselves on having, or at least having had, the opportunity, to a certain extent, of carrying them out (I admit very inefficiently) ever since the passing of the Leeds Improvement Act, in 1842. The question, then, arises, which it would be foreign, perhaps, to this place to discuss, which is the best mode of carrying them into effect?-whether a local board can act more efficiently than a central one? As a general rule we must admit that such matters ought to be under the controul of those who have to bear the expense of them; but in those places and towns where the authorities and public neglect their duty, a central board or governing body surely may safely be allowed to interfere. 
I have now brought my sketch of the progress of public hygiène down to the present time; and if we may judge from the valuable reports that are constantly in the course of being made to the General Board of Health, as appointed to carry out the Public Health Act and the Epidemic Diseases Prevention Act, we may fairly assume that public hygiène is making rapid progress; and that as rapidly as its ardent supporters could desire, and as prudence would dictate; for in carrying out new measures concerning the interests of large masses of the people, we must proceed on sound and well-established data, and in accordance with the result of practical as well as scientific research, or we shall retard the measures we are anxious to accomplish, and impede the grand, and till recently little studied, question of sanitary reform. In justice to the writers of the valuable reports we have just alluded to, it would have been an om:ssion not to have named and called your attention to them; and those who wish for really instructive and, I may add, interesting information on such matters will do well to refer to them. The breaking out of the cholera in 1848 ( 72,000 deaths) of course gave a great impetus to this question, and some of the most recent sanitary reports are principally upon epidemic cholera,-its kistory, causes, progress, prevention, \&c. The reports of Mr. Grainger and Dr. Sutherland are most valuable, full of useful matter, and deeply interesting. And without entering into any discussion as to the origin and prevention of the cholera-a subject which many are inclined (in my opinion erroneously) to think that we know as little about as ever, for I may venture to assert that the result of the most searching inquiries, reports, and investigations of so many able observers, is to show, now, that we are in a position easily to collect facts and draw conclusions, that it is in the power of man, and Providence has placed at his disposal obvious and adequate means for materially lessening, if not altogether preventing, this fearful scourge. Facts innumerable prove that overcrowding, want of pure air, offensive effluvia and exhalations, drunkenness, impure water; unwholesome or insufficient food, intemperance, and fatigue are the determining causes of the invasion and spread of cholera. The recent reports show and prove this beyond all doubt; and equally decidedly prove that sanitary ameliorations have invariably been found active in the mitigation and diminution of choleraic disease. The thinning of a crowded population, the suppression of nuisances, the removal of refuse, the lime-washing of dwellings, the supply of good water. which was scanty or unwholesome, have invariably been followed, and often very promptly, by a diminution and even cessation of sickness. I could name a number of towns where this has taken place; for, as has been truly said, in a recent number of the British and Foreign Medico-Chirurgical Review for June, 1851, "Never was there a disease in which the finger of Providence has been more conspicuous than in epidemic cholera. Its whole career manifests that it is a divine judgment, not indeed an infliction of wrath, but a chastisement of rebuke. We have been long neglecting our duties to the poor, and to those that cannot help themselves. Thousands upon thousands are annually swept away by diseases which are more or less under control, or even prevention. What did Dr. Rush say between sixty and seventy years ago? His words are pregnant with meaning:-'To all natural evil, the Author of Nature has kindly prepared an antidote. Pestilential fevers furnish no exception to this remark. The means of preventing them are as much under the power of human reason and industry as the means of preventing the evils of lightning and common fire.' And has not experience confirmed the accuracy of his statement? But have we acted in accordance with the duty which the knowledge of its truth imposes? Or have we not rather, in spite of conviction, allowed the most monstrous physical evils to spring up in our towns and villages-evils that inevitably produce disease, wretchedness, and death? A new and fearful messenger has been sent into our land to alarm and warn us. Hitherto the judgment has been tempered with mercy; we have had but a simple duty to do, and but a few simple rules to obey, and the invasion of the pestilence has been comparatively innocuous. It only requires the will of Him who sent it to intensify its virulence by some degree, and its poisoned breath may spread destruction even in the purest and healthiest localities. Who can say that the third visitation may not come armed with treble power? Does not the history of the ways of Providence in past ages lead the thoughtful inquirer to believe that such will be the ease, if duties are left undone and privileges remain unimproved. All classes of the community are deeply interested in the inquiry. How much should it then engage not only the serious attention, but also the active and serious labours of the members of that noble profession the great end and object of whose mission is to save life, mitigate suffering, and ameliorate the condition of their fellow-man."

Besides the reports and investigations of Mr. Grainger and Dr. Sutherland, the labours of our metropolitan and provincial brethren,* when the epidemic existed so generally, all parties must admit were beyond all praise, so that it would seem invidious further to give names; but I only make the exception when they refer to writers of official and special reports. Under this head I must name Drs. Burke, Milroy, Lewis, Hector Gavin (the laster, I believe, recently sent by Government to Jamaica, to treat the disease,) Mr. Simon, the Officer of Health for the city of London, (who has been facetiously termed by Punch, the real "Simon Pure,") and others, whose reports are most useful and suggestive.

The names and labours of Lords Carlisle and Ashley, (names ever found in connexion with what is ennobling,

- A number of local reports, treatises and essays on cholera-its origin, statistics, termination, and treatment, \&c., in different loes'ities, have appeared from time to time from the pens of medical men. One by Dr. John Taylor, of Huddersfield, most satisfactorily discusses this subject, and his views agree with those of Dr. Sutherland and Mr. Grainger. Dr. Budd has written "On its Propagation and Prevention;" Mr. Brittan "On its Pathology," \&c., and many others. 
useful and philanthropic,) Dr. Southwood Smith, and Mr. Chadwick, are both known and appreciated, and they form the General Board of Health, from whose reports and suggestions we have a right to expect great things; still we must admit, these, in themselves, are comparatively worthless unless the public are influenced by them, take them up, and carry them into practice; hence one of the great objects of a paper like this should be to call attention to these reports and recommendations. Before alluding to the most recent publications of the General Board of Health, I may state, that in 1847 a valuable document appeared in the Report of the Metropolitan Sanitary Commission, written by Sir William Clay, and entitled, "Remarks on the Water Supply of the Metropolis, and was both opportune and useful; as well as that of Dr. Robert Angus Smith, entitled "Report on the Air and Water of Towns." The recent Report of the General Board of Health on "Quarantine," as well as their letter to the Lords of the Privy Council, "On the Practice of Quarantine in England," deserve an attentive study, and as fairly and ably discuss the question as a comparatively nop-medical board can be expected to do, but the complicated and delicate questions of contagious and non-contagious disease, and the utility of quarantine, are still questions to all impartial minds and careful observers, sub judice. (A congress of Savans is now sitting in Paris, to report upon the supposed contagious and infectious disorders, and on the practice of quarantine, \&c.)

The reports of Dr. Sutherland and Mr. Grainger " On Cholera," are models of what such documents should be ; and why the labours of such men, along with many others of the medical profession, are not as deserving of the rewards and honours of the State, as those of mere political partizans and agitators, or caterers for public amusement is, I think, difficult to explain. But surely we are on the eve of better times, and due regard will henceforward, as respects State patronage and emolument, be paid to the just claims and arduous duties of the medical profession. The lawyers are sure of many prizes, and those the highest the State can award, and have an especial dislike to see the finger of reform pointed to their profession and their musty, multitudinous, and confusing documents and acts; all the snug berths created by our laws, are mostly in the hands of the lawyers. And the divines, (I say it with all respect,) have a peculiar attachment and eye to a good living, and to the distinctions, titles, and rank, to be found connected with the government of the Church; and the heads of it certainly cannot, with propriety, apply to themselves the striking words of the highest authority - "Silver and gold I have none," whilst the members of our profession, with few and rare exceptions, can never look forward to either State patronage or emolument, to honorary titles or distinction, still we are mulcted to the support of that State in the same proportion as if our incomes were as safe and certain. But $I$ am digressing. Besides the reports referred to, $I$ have to name in particular, the two recent ones, $(1850$,) that of Dr. Sutherland, "On a General
Scheme of Extramural Sepulture," and that "On the Supply of Water to the Metropolis." Both these important publications will do much towards an exten: sion of public hygiène. Both these documents will amply repay an attentive perusal, and the reader will not fail to become, not only instructed, but really interested in these important inquiries. A review of the " Report on Extramural Sepulture," has recently appeared in the British and Foreign Medico-Chirurgical Review, which contains some really beautiful writing. A few of the sentences referring to this subject I here introduce, as they struck me forcibly at the time of reading them, and I am sure they are well worth repeating. The reviewer writes :- "A fastidious and sensitive mind might perhaps find something to wound its susceptibility in the mode of conducting the funeral rites of most nations. It might not find any solemnity sufficiently awful-any ceremonial adequately expressive to fulfil its conception, as to how the last duties should be paid to the earth about to return to its kindred elements. It might find something repugnant in the sudden dispersion of the atoms of the frame so lately gifted with vital motion, by the flames of the funeral pile; it might equally object to the mockery of preserving these inanimate atoms as if the art of the embalmer could obliterate the ineffaceable seat of the King of Terrors. But if a curious inquirer should deem it worth his while to glance over the funeral rites of ancient or modern times, he would find that, however, in some points, they may fall short of his conception, such ceremonials have always been conceived in a spirit of grand and solemn poetry. The Greek, crowned with flowers and stretched on his last couch, formed with fragrant and precious woods, as if the flames which were to consume him should spring from no common source;-the Brahmin carried solemnly to the banks of his sacred stream, and then gently committed to the purifying waves; - the Scotch Highlander, buried at night, by the light of the torches of his Clan;the Red Indian covered with his trophies;-the savage, laid in his solitary forest grave, amid the melancholy sound of the wailing death-song of his tribe, present so many examples of the same spirit of remorse, grief, and humility, which led the early Christian Church to throw around the burial of the dead, that most impressive ceremonial, on which are so marvellously blendedsorrow, pity, and hope for the departed, and warning and admonition for those whose turn must shortly come. Even those nations which we in these days of boasted progress, are accustomed to regard as little better than barbarians (just emerging from the shade of their primitive forests), exhibit for the most part, in their present solemnities, a spirit of which Christian communities could not be ashamed. The sh : tness of life, the frailty of mortality, the dread myster, of that strange secret, which all men must sometime know, impress the Caffre or the. Dyak no less forcibly than the Briton or the German.

The customs of our own country, if they cannot vie in grandeur and impressiveness with the stately ceremonial of the Assyrian,"andithe Greek, are yet 
impressive and solemn, and have a more lasting, if not so immediately thrilling, an effect. In order to encourage these devotional feelings still more, the Church, in the eighth century, commenced the practice of aliowing the dead to be buried in the vicinity of the churches, so that at once the body might be laid in undistur'bed and consecrated ground, and the survivors might associate that holy spot with the place in which they assembled to discharge the rites of religion. In this way, also, as the churches stood generally at some little distance from the mass of dwellings, the resting place of the dead was not disturbed by the harsh and discordant murmurs of the exciting bustle of those who had succeeded at the feverish strife and turmoil of existence. When, indeed, one of the active agents in life's May game turned his footsteps for one moment into the still inclosure, shaded by its funeral boughs, he could not fail to be recalled, by the quiet sanctity of the place, to a recollection of the doom which awaited him, and of the mode of life which ought to be a preparation for that fate.* So also the bodies of the dead were then allowed to resolve themselvs into their original atoms without the living suffering from the inevitable emanations, for as every inch of ground was not, in these days, worth its weight in gold, the cypress and the yew were permitted to plunge their purifying roots into the ground, and to transmute into their own beautiful forms those particles which had ceased to constitute the fleshly temples of immortal souls. Nor were these rites, this ceremonial, these influences in the minds of the survivors, intended for one single clisss of the community. The Christian Church, knowing no differences of rank on the day when the common lot has rendered such differences impossible, whether poor or rich, there was devised the same farewell for the dead, the same solemn admonition for the living. The rich man :night, indeed, sleep in his vault, and the ' rude forefathers of the hamlet,' in their graves of turf, but the same influence sanctified both, and the simple cross over the mound of earth was as sacred as the marble sepulchre, or the heraldic pomp engraved on brass. Knowing, then, the intention of the Church, and consulting the feelings of our nature, by keeping uncontaminated and undisturbed the relics of mortality, how needful was it for the State to interfere in order to prevent the unholy and almost inhuman mode in which interments too often take place in the midst of London and many of our other large cities. If you read the report on Extramural Sepulture and Evidence on Interment in Towns before Parliament, and the praiseworthy reports of $\mathrm{Mr}$. Walker on this subject, the mind

- A.D. 740 Cuthred, brother to King Etherard, succeeded him in his Dominions, and was much disquieted by Edilbald, King of Mercia, both by open war and privie practises; but these two Kings coming to a conclusion of peace, joyned both their powers against the over-borne Britaines, and in a bloody battle gave them a great overthrow. In this time saith Beda, the bodies of the dead were permitted to be buryed within the walles of their cities, which thing before was not lawfull, but their corps were interred without in the fields; many of whose tombs are as yet wituesses to us, that daily find them in digging of the grounds adjoyning and reserve them for sight or other necessary use.-Speed's History of Great Britaine: Third Bdition. 1632: p. 229. (This note was sent me by a medical student. - I.) feels horror, astonishment, and disgust at the mode in which, in the nineteenth century, and in the centre of the civilized world, funeral obsequies are conducted in the English metropolis, in which 52,000 bodies have annually to be disposed of. During the last 150 years, and particularly in the last half century, London has been literally rising like magic out of the earth. On all sides the suburbs and the open courtry around have been invaded by its new streets. Churches built even lately, and thename of which often signifies that they stood in fields, now stand almost in the heart of the city; the dwelling-houses are carried up to the churchyard walls. (and this is not confined to London, but is the case in most of our large old cities and towns,) and the habitations of the living, and the abodes of the dead, are in the closest proximity. Thence it comes that the silence of the graveyard is violated by the hum of common life, and the stillness of the tomb is a phrase which has no meaning. The old solemnity of the burial place becomes destroyed, and the steps of men, absorbed in the cares of trade and speculation, cross, without a moment's reflection, the repositories of their departed friends and relatives. The exact state of matters in London has now been so completely laid open and exposed, that common prudence and decency forbid the continuance of intramural interment, and the Board of Health have (thanks to Mr. Walker and others) now proposed to deal boldly with the question, and have brought forward an efficient mode of remedying such a feurful evil ; it is, "that every existing graveyard in London is to be closed, no more bodies are to be thrown (for it is nothing more) into them; burial grounds are to be made outside the city, apart from the busy tread of men and the hum of commerce, and these burial places, are to be rendered easily accessible even to the poorest. The pauper will be then carried there as solemnly as the peer, and buried with equal decorum; the exhalations of the ground will no longer exert a poisonous influence, and the burial grounds themselves will present the appropriate character of the mausoleum of a great city."

To fulfil these conditions the Board proposes to form a vast cemetery at Erith-on-the-Thames, several miles below London, and to enlarge Kensal Green and the other cemeteries. The advantage of having the principal cemetery at Erith, is its easy access by water, its distance from London, and the existence of a suitable piece of ground. The Board proposes, also, to have receiving houses at convenient distances on the banks of the Thames, to which the relatives may convey the body, afterwards to bes placed on board a steamer for conveyance to Erith.

If these measures are carried into effect, along with an adequate supply of pure water to London, " the Board will have accomplished the first of a series of social changes, which will be without parallel in the beneficial effect they will produce in the dense masses of the labouring classes."

If, then, it is found practicable in London, with its population of above two millions, to dispense with intramural interment, and to provide an adequate 
supply of water at all hours, for the use of the inhabitants, surely there is no excuse for any town in England remaining behind London in the promotion of such necessary sanitary measures. With regard to a supply of water, we may add, in the words of the Times, " that it is now a plain and fundamental maxim of sanitary economy, social policy, and good government that the water we use should be no more an article of trade or taxation than the air we breathe or the light we enjoy." Thanks to the exertions of the sanitary reformers we are now promised light-that boon of Heaven-without paying a tax for the use of it.

[To be continued.]

ON THE

\section{INEFFICACY OF KOUSSO IN SOME} CASES OF TANIA.

\author{
By EDWARDS CRISP, M.D., LoNDoN.
}

Read at the Nineteenth Anniversary Meeting, held at Brighton, August, 1851.

Case 1.-On February 20th, 1851, at the Metropolitan Dispensary, I gave this medicine to a boy, aged 6, who I thought had been cured by turpentine some months before. He took in my presence, at different times, three doses; two of two drachms, and one of a drachm and a half, but no portion of the worm was expelled. He now passes joints of the worm frequently.

Case 2.-February 28, 1851.-A girl, aged 12, took two doses of three drachms each, and nine feet of the worm were expelled. She has up to the present time had no return of the complaint. This patient I had also administered turpentine to, and I supposed she was cured by it. The second dose of the medicine produced a great deal of griping pain.

Case 3.-Mrs. T., aged 59, came to the dispensary May 20th, 1851. She has been affected with tapeworm for eight years. Three years ago she had a convulsive fit, and lost the use of her side for three weeks. Has taken no anthelmintic. I gave three drachms of kousso, and in six hours thirty feet of the worm came away; and at present she appears to be cured. This patient had also deafness, palpitation of the heart, and partial loss of sight.

Case 4.-W. R., aged 59, applied at the dispensary May 16th, 1851. Has had tænia for three years. Twelve months since took turpentine; but it produced tenesmus and great pain on micturition. I ordered him half an ounce of kousso, and thirty-three feet of the worm passed after five or six hours. But in this and the other cases the head was not found. This man came to the dispensary a fortnight since, and brought several joints of the worm, that had escaped per anum. I have ordered him two doses of the oil of turpentine, but I do not yet know the result.

During the last two years, at the Metropolitan Dispensary, I have prescribed for thirteen cases of tænia, Ten of these patients took turpentine, and seven appeared to be cured. In one no beneficial effect was produced by it ; and in two, the worm, although apparently removed after the turpentine, was not all expelled. The latter patients (cases 1 and 2) afterwards took the the kousso. One patient was pregnant, and therefore anthelmintics were not prescribed.

I conclude, from the above evidence, that kousso does not always remove the head of the worm; and that it cannot be considered a specific for tænia ; that its action is milder than that of turpentine, and the greater part of the parasite is generally removed en masse by it; but it is questionable whether its efficacy in tænia is much superior to that of turpentine, which, when first employed, was also lauded as a specific.

THE LEFT ARM AND HAND OF A CHILD FOUND IN A STATE OF PU'IRESCENCE, FROM STRANGULATION, THE FUNIS BEING TIGHTLY BOUND ROUND IT AT THE UPPER PART.

\section{By A L B R T O W N, Esq., Aylesbury.}

ON the 3rd of June last I was sent for to a woman, the mother of four children, who was miscarrying in the seventh month of her fifth pregnancy. I found the membranes ruptured, a large discharge of the liquor amnii to have taken place, and the labour pains occurring every fifteen or twenty minutes. There was not any flooding, neither could I, by examination, feel the child. She continued in this condition for another six hours, when the pains ceased, and she went on with her pregnancy to the full period of gestation, without any other inconvenience besides what she termed a constant "dribbling of the waters." On the 27 th of July, two months after, I was again hastily summoned, and found the pains strong and regular, the os well dilated, but no portion of the child to be arrived at by mauual examination. I, therefore, gave her a dose of the pulverized secale cornutum, which had the effect of increasing the strength of the pains; and in less than half an hour I discovered a hand outside of the vagina, and the head tightly wedged against the brim of the pelvis. All attempts to return the hand, or to pass my own, so as to turn the child, were perfectly useless; aud $I$, therefore, resolved to leave the management of the case for the next half hour to natuie, when, much to my satisfaction, as if under some violent and sudden impulse, the uterus discharged the whole of its contents with such force that the fœtus and placenta both came away en masse. The child was dead, appar ntly not many hours, but the entire of the left upper tremity was in a shrivelled, livid, and putrid condiiion, the funis tightly bounil round and imbedded in the upper part of it, just below the insertion of the deltoid ; in fact, the limb did not appear much more than half the size of its fellow on the other"sile. The mother had a gool getting up, and seemed none the worse two days afterwards. 